\title{
Effects of age, parity, and pregnancy abnormalities on foal birth weight and uterine blood flow in the mare
}

\author{
Klewitz, J ; Struebing, C ; Rohn, K ; Goergens, A ; Martinsson, G ; Orgies, F ; Probst, J ; Hollinshead, \\ $\mathrm{F}$; Bollwein, Heiner ; Siemens, H J
}

\begin{abstract}
Color Doppler sonography has become routine for the evaluation of high-risk pregnancies in human medicine. Previous studies documenting uterine blood flow parameters in the pregnant mare have found a decrease in peripheral blood flow resistance in the first pregnancy weeks and an increase in uterine blood flow, especially in the last trimester of pregnancy. However, these studies involved only a small number of mares. No naturally occurring pregnancy abnormalities occurred that would allow blood flow changes to be retrospectively examined and analyzed. The objective of the present study was to monitor the diameter of the uterine artery, uterine blood flow, and the combined thickness of the uterus and placenta (CTUP) throughout gestation in a large number of pregnant mares of different age and parity. In the present study, 51 warmblood mares were examined by ultrasonography on Days 16 and 30, at monthly intervals until Day 300, and then every 10 days from Day 300 until parturition. After localization of the uterine artery ipsilateral and contralateral to the conceptus, the diameter of each artery, the uterine blood flow (pulsatility index [PI], blood flow volume [BFV], and the presence of early diastolic notch), and the CTUP were measured and correlated to placental and foal birth weight after delivery. Furthermore, the effect of age $(3-7$ years $[\mathrm{n}=16], 8-11$ years $[\mathrm{n}=17], 12-16$ years $[\mathrm{n}=18])$ and parity $(0-2$ foals $[\mathrm{n}=22], 3-4$ foals $[\mathrm{n}=15], 5-8$ foals $[\mathrm{n}=14])$ on these parameters were analyzed. The diameter of the uterine artery increased more than threefold in the ipsilateral artery $(0.40 \pm 0.07-1.33$ $\pm 0.08 \mathrm{~cm})$ and 2.7 -fold in the contralateral artery $(0.39 \pm 0.07-1.07 \pm 0.08 \mathrm{~cm}[\mathrm{P}<0.0001])$. The early diastolic notch disappeared in the pulse waves in $98 \%$ of the ipsilateral arteries and $85.7 \%$ in the contralateral arteries on Day 150 when placentation is complete. Blood flow volume increased 50-fold in the ipsilateral artery during pregnancy and increased dramatically in the last trimester. The median foal weight was $52.6 \mathrm{~kg}$. Mares with heavier foals $(>52.6 \mathrm{~kg}$ ) had a 1.38-fold higher BFV in the last 2 months $(\mathrm{P}<0.05)$ compared with lighter foals. Pulsatility index decreased 2-fold until completion of placentation at around Day 150 and continued to decline until Day 240 where it then stayed constant and at a low level until delivery. Age predominantly influenced PI, whereas the diameter of the uterine arteries, which is correlated to BFV ( $\mathrm{r}$ ipsilateral $=0.919, \mathrm{P}<0.0001$ and $\mathrm{r}$ contralateral $=0.909, \mathrm{P}<$ 0.000), was strongly affected by parity. Four mares spontaneously aborted (Days 200, 208, 213, and 246) and four mares spontaneously developed placentitis that was diagnosed by the presence of an increased CTUP and/or placental pathology after delivery. Although not statistically relevant, the aborting mares showed a slightly increased total BFV, but no differences in PI were seen compared with mares without abnormalities of pregnancy. Mares that developed placentitis had a late (Days 150-210) disappearance of the early diastolic notch and an increased PI in the first half of pregnancy. In conclusion, the study documented differences in uterine artery diameter and blood flow in a large number of pregnant mares. Furthermore, this is the first known report to document uteroplacental blood flow changes associated with naturally occurring placentitis and abortion in mares.
\end{abstract}

DOI: https://doi.org/10.1016/j.theriogenology.2014.11.007 
Posted at the Zurich Open Repository and Archive, University of Zurich

ZORA URL: https://doi.org/10.5167/uzh-107170

Journal Article

Supplemental Material

Originally published at:

Klewitz, J; Struebing, C; Rohn, K; Goergens, A; Martinsson, G; Orgies, F; Probst, J; Hollinshead, F; Bollwein, Heiner; Siemens, H J (2015). Effects of age, parity, and pregnancy abnormalities on foal birth weight and uterine blood flow in the mare. Theriogenology, 83(4):721-729.

DOI: https://doi.org/10.1016/j.theriogenology.2014.11.007 


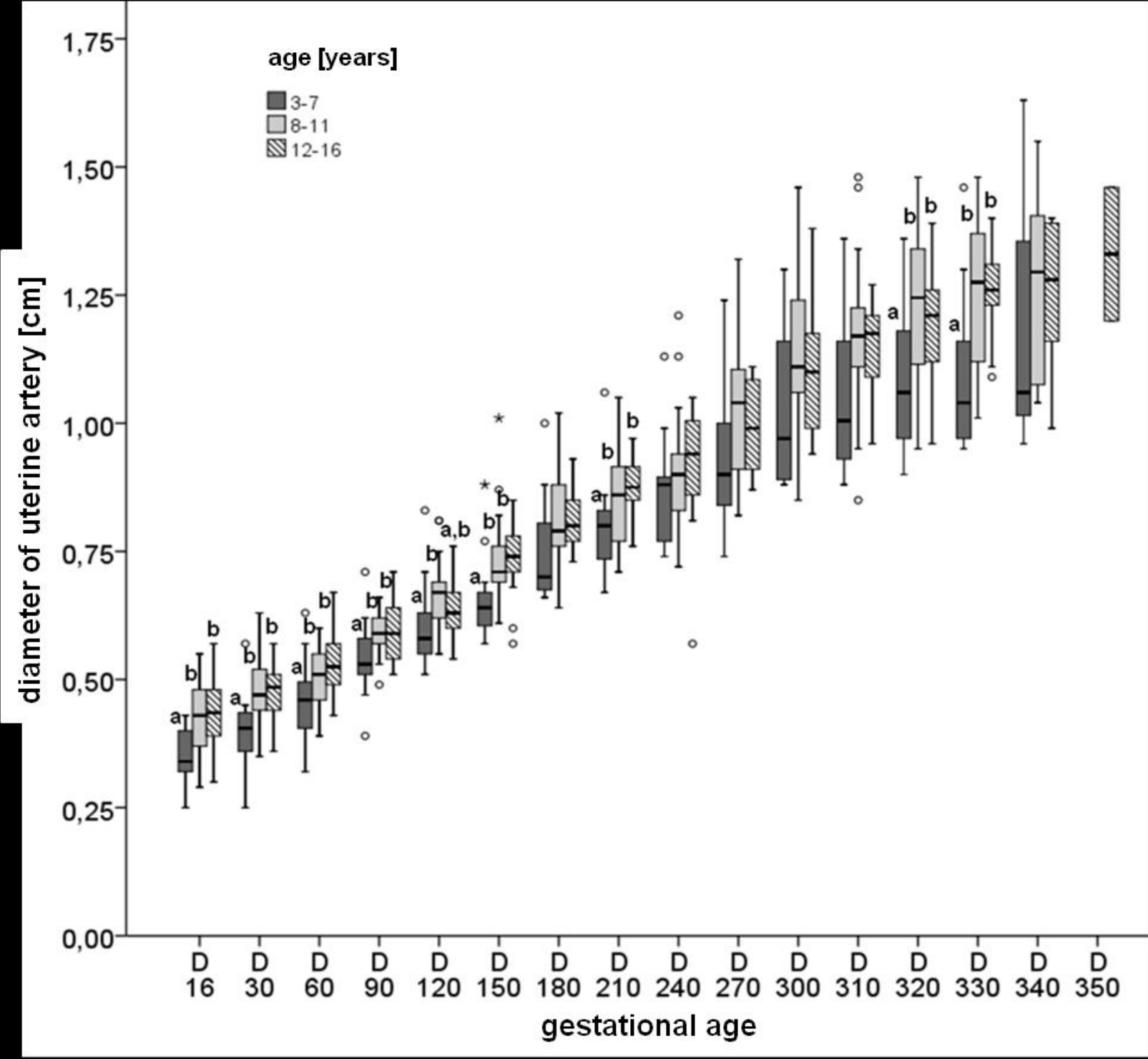

